
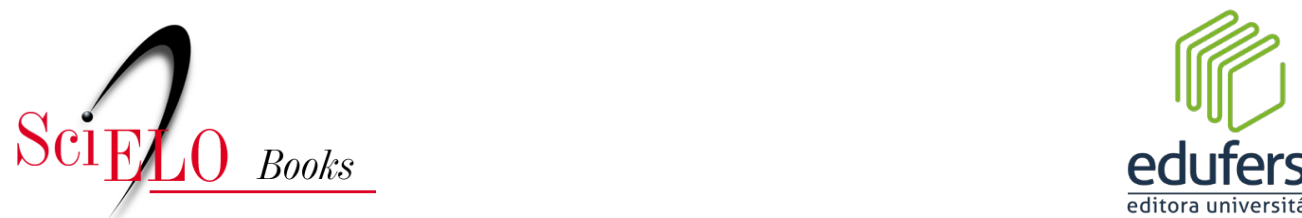

edufersa

editora universitária

\title{
12 - Questão agrária colombiana e as economias sociais do comum - ecomum
}

\author{
Maria Rosana da Costa Oliveira \\ Cláudio Ubiratan Gonçalves
}

\section{SciELO Books / SciELO Livros / SciELO Libros}

OLIVEIRA, M. R. C., and GONÇALVES, C. U. Questão agrária colombiana e as economias sociais do comum - ecomum. In: OLIVEIRA, G. M. C., and VIEIRA, K. M. A., eds. Patrimônio, povos do campo e memórias: diálogos com a cultura, a arte e a educação [online]. Mossoró: EdUFERSA, 2020, pp. 179-192. ISBN:

978-65-87108-09-4. https://doi.org/10.7476/9786587108605.0013.

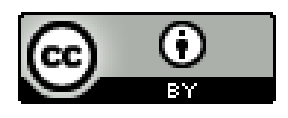

All the contents of this work, except where otherwise noted, is licensed under a Creative Commons Attribution 4.0 International license.

Todo o conteúdo deste trabalho, exceto quando houver ressalva, é publicado sob a licença Creative Commons Atribição 4.0.

Todo el contenido de esta obra, excepto donde se indique lo contrario, está bajo licencia de la licencia Creative Commons Reconocimento 4.0. 


\section{QUESTÃO AGRÁRIA COLOMBIANA \\ E AS ECONOMIAS SOCIAIS DO \\ COMUM - ECOMUM}

Maria Rosana da Costa Oliveira

Cláudio Ubiratan Gonçalves

\section{Introdução}

Este texto resulta de parte do relatório desenvolvido no DoutoradoSanduíche (PDSE) realizado na Universidade Externado de Colômbia, onde tive a oportunidade, através de aulas e trabalhos de campo, discutir o espaço agrário colombiano e conhecer experiências alternativas ao modelo de desenvolvimento agrário/agrícola adotado no país.

Reconheço os limites e a complexidade que essa análise requer e busco caracterizar aspectos mais gerais sobre a questão agrária, como a alta concentração de terras, a especulação estrangeira, a violência, a expulsão e a ausência de políticas públicas para os camponeses. Em meio ao conflito presente no espaço agrário colombiano, apontamos experiências conhecidas ao longo dos trabalhos de campo, mas priorizamos a análise da cooperativa Ecomum, resultante do acordo de paz assinado entre as Forças Armadas Revolucionárias da Colômbia (FARC) e o governo Manuel Santos. Essa cooperativa foi escolhida pelos ex-combatentes como meio coletivo de reinserção social e econômica.

Baseada nos princípios da Economia Solidária (autogestão, respeito à natureza, cooperação, solidariedade, comércio justo, outros), a Ecomum tem como base produtiva as atividades agrícolas (criação de búfalos, piscicultura, plantio de milho, mandioca, laticínios, cafeicultura, outros). 
É desafiante o trabalho dessa cooperativa diante do não cumprimento de pontos essenciais do acordo, como o acesso à terra, a disponibilidade de infraestrutura, energia, água, apoio técnico, questões que limitam o fortalecimento econômico e social das cooperativas. Sem deixar de mencionar a violência e a perseguição aos ex-combatentes, que até o mês de março de 2020, contabilizavam 194 mortes.

Reconhecemos o avanço que o acordo de paz representou para a Colômbia após quase 50 anos de conflito armado. No entanto, a concentração da terra e dos seus bens comuns (água, ar, subsolo) voltados para o agronegócio e para especulação estrangeira ainda é uma realidade presente na Colômbia. Quatro anos não foram capazes de permitir o acesso e a titulação do que fora prometido. Por isso os/as ex-combatentes continuam lutando e resistindo com os pés sobre a terra.

\section{A questão Agrária Colombiana}

De acordo com relatório realizado pela OXFAM (2017), embora tenha ocorrido a redução da pobreza nos últimos 12 anos, Colômbia ainda apresenta alto nível de concentração de terras e aumento da desigualdade socioeconômica. Segundo Rodriguez, Camacho e Morales (2017) o processo de concentração de terras na Colômbia, é governado por lógicas históricas, econômicas e culturais devido à contínua expansão das fronteiras espaciais e territoriais (em lotes vagos nacionais, bens de uso público, terras privadas, territórios comunitários) e o controle do trabalho para acesso a novas fontes de recursos e riqueza.

Ainda segundo os autores, no final do século XX, especificamente em 1996, 45\% das terras do país estava nas mãos de $0,4 \%$ dos proprietários, enquanto o 4,3\% da superfície da terra correspondia aos $70 \%$ dos proprietários. Em 2002 cerca de $70 \%$ dos proprietários de prédios menores a 5 hectares contava com $4 \%$ das terras do país, enquanto $0,4 \%$ dos proprietários contava com $46 \%$ das propriedades.

Os dados apontam como as leis agrárias do século XX foram ineficazes na melhoria e equilíbrio da estrutura da propriedade, pois provocaram apenas a alta desigualdade existente. Essa desigualdade gerou uma série de conflitos por terra e território resultando em violência nos territórios 
camponeses, indígenas e afro-colombianos. A ausência estatal e a intensa repressão aos movimentos campesinos contribuíram para o surgimento de guerrilhas que historicamente têm operado principalmente em territórios de colonização e fronteira com limitada presença estatal. Destacamos as Forças Armadas Revolucionárias da Colômbia (FARC-EP) e o Exército de Libertação Nacional (ELN).

Além da violência provocada por guerrilhas rurais, paramilitares, no campo colombiano percebe-se o aumento da apropriação de terras e de bens comuns, por parte de investidores empresariais nacionais e estrangeiros, em detrimento das populações campesinas e pequenos produtores rurais em clara violação de suas formas consuetudinárias de acesso e uso da terra e seus direitos; processos que vem ocorrendo em terras da África e América do Sul. Denomina-se "acaparamiento" de terras, cujos efeitos sociais junto com a violência que assola o espaço agrário, têm causado o aumento da expulsão da população do campo. Segundo os dados do Centro Nacional de Memória Histórica (CNMH) publicados em 2015, estima-se que, nas últimas cinco décadas, mais de 7 milhões de pessoas (13\% da população) foram forçadas a deixar seus locais de vida e se mover à força para cidades e outras regiões.

A atual configuração do campo agrário colombiano em benefício do setor agroindustrial reforça a disputa de terras e a pressão entre camponeses e latifundiários. De acordo com Darío Fajardo (2009) "O documento mais subversivo produzido nos últimos anos na Colômbia é o censo agrícola nacional de 2014", a partir do qual é possível visualizar a concentração da terra, na área produtiva e na pastagem, e a pequena área destinada a chamada agricultura familiar camponesa.

Conforme os dados apresentados pelo Departamento Administrativo Nacional de Estadística (DANE) sobre o uso da terra, a maioria das grandes propriedades é caracterizada pela subutilização da terra, em grande parte destinada a criação do gado de modo extensivo, que, além de uma contribuição nula à criação de empregos intensifica a deterioração dos solos e uma série de implicações ambientais. Desígnio estatal que amplifica a pobreza rural, a insegurança alimentar e a violência em todas as regiões do país. 
Segundo Rodriguez (2015) existe dois tipos de ordenamento territorial nos dois espaços e nos dois modelos de desenvolvimento: o do agronegócio e o da pequena economia camponesa familiar e das economias próprias. Um que tende a ser mais subordinado à reprodução da vida no mesmo território e à sua sustentabilidade; e um arranjo territorial implantado com o princípio de eficiência, competitividade e geração de excedentes, atividades que chocam com formas preexistentes de apropriação do espaço e em particular do usufruto territorial.

De acordo com Bartra (2017) durante os séculos XIX e XX as mulheres e homens do campo combateram de distintos modos por terra e liberdade. Hoje o combate rural mais visível e defensivo é travado nos chamados territórios: espaços em disputa onde as comunidades indígenas e mestiças buscam preservar seu patrimônio e sua vida, ameaçadas por gananciosas corporações.

Dados apresentados por Barbieri (2011) apontam que embora somente $33 \%$ das terras estejam destinadas aos camponeses, estes contribuem com $51 \%$ da área colhida e $49 \%$ da produção agrícola, o que permite concluir que a produtividade por hectare na pequena produção camponesa é muito alta. De acordo com Fernandes (2014) apesar da pouca terra disponível para os camponeses, a Colômbia é o único país da América Latina onde os agricultores de base familiar produzem mais que a agricultura industrial capitalista. São responsáveis por $41 \%$ do valor da produção e $57 \%$ da oferta dos postos de trabalho.

Esses dados demonstram as potencialidades do modo de produção camponês como o aumento do emprego, a produção de alimentos sãos e o respeito a natureza, contrariando à aposta atual dos Estados Nacionais dos países latino americanos que optam pela acelerada expansão do modelo do agronegócio exportador de matérias primas, que explora a vida e os bens comuns (terra, água, ar, outros).

Diante desse modelo, o campesinato é essencialmente o símbolo e o sujeito sociopolítico da resistência (BARTRA, 2011). Mais do que resistência, que significa reagir a uma ação anterior e, assim, sempre uma ação reflexa, temos re-existência, quer dizer, uma forma de existir, uma 
determinada matriz de racionalidade que age nas circunstâncias, inclusive reage, a partir de um topoi, de um lugar próprio, tanto geográfico como epistêmico (GONÇALVES, 2011).

Quase dois séculos de história do capitalismo no campo não foram suficientes para destruir essa classe social e cada vez mais demonstra não ser o único modelo de desenvolvimento da Agropecuária. Alternativas estão sendo construídas nos territórios de vida como estratégia de resistência, em comunidades indígenas, camponesas ou afro colombianas, que resistem em seus espaços mesmo com toda pressão estatal (dimensões federal, estadual e municipal), multinacional, paramilitar ou de dissidentes de guerrilhas ainda presentes na Colômbia.

Segundo Fajardo (2009), no espaço agrário colombiano, existem diferentes experiências de organizações camponesas que desenvolvem formas de produção comunitária. O modelo mais recente são os conselhos comunitários afrodescendentes que foram reconhecidos na constituição de 1991. Há experiências da economia indígena que são historicamente diferentes da tradição de povos nativos, outra tradição dos camponeses mestiços, outras dos povos afrodescendentes.

Priorizo a análise da organização Ecomum, porém não poderia deixar de citar brevemente experiências com as quais tive contato ao longo do estágio e que também demonstram a resistência camponesa através de atividades em Economia Social Solidária. Entendo que esta economia se configura enquanto alternativa de manutenção e reprodução das famílias no campo, pois através da sustentabilidade econômica e ambiental seria capaz de superar os entraves e as consequências negativas deixadas pela modernização da agricultura, dentre elas, o êxodo rural e a destruição do patrimônio ambiental.

Destaco a participação no Foro "Economias Propias y Agricultura Campesina, Familiar y Comunitaria" onde pude conhecer experiências da Associação de Conselhos Comunitários do Cauca (ANCOC). Dentre elas, a produção e exportação de panela orgânica por quilombolas que mesmo com dificuldades e enfrentamentos às multinacionais do setor da cana, produziam em seu território e exportavam para países como México e Espanha. 
Em Madrid - Cundinamarca - tive a oportunidade de conhecer a Associação Herrera, criada em 2011, composta exclusivamente por mulheres que buscam hoje alternativas de produção e comercialização de leguminosas, flores, plantas medicinais, em oposição ao trabalho realizado anteriormente no agronegócio de flores presente na região, este que provocou vários danos a estas mulheres.

A partir destas experiências, entendo que a produção camponesa vem sendo inserida em novos mercados e novos circuitos mercantis. Ou seja, novas formas de cooperação local estão sendo descobertas. E os valores imateriais devem ser levados em consideração, como a reciprocidade e a solidariedade.

\section{Acordo de paz e o surgimento das Economias Sociais do Comum - Ecomum}

A partir do 'acordo de paz' firmado em 24 de novembro de 2016, as cooperativas em Economia Social e Solidária (ESS) passam a ser uma alternativa de reincorporação dos e das ex-combatentes no período pós-conflito. A cooperativa Economias Sociales del Común (ECOMÚN) foi criada com esse objetivo e seu trabalho vem sendo realizado desde setembro de 2017; sua função se estende a receber, administrar recursos de reintegração individual e coletiva, apoiando as cooperativas criadas em todo o país. Atualmente opera com mais de três mil ex-combatentes associados.

A espacialização da Ecomum se dá em nível nacional. Conta com aproximadamente 127 cooperativas, 30 delas legalizadas. Com 5.076 associados, 3.468 homens e 1.374 mulheres. Em sua maioria, são cooperativas multiativas e têm como base atividades agrícolas (criação de búfalos, plantio de batata, milho, macaxeira, avicultura, piscicultura, lacticínios, cafeicultura, artesanato, outros).

A base de ação a nível produtivo, social e econômico se orienta para promover a economia popular, campesina, social e solidária como modelo alternativo para o sustento da vida coletiva dos territórios. De acordo com Razeto (1997), a chamada "economia camponesa", com suas unidades familiares ampliadas, suas articulações em nível territorial e comunitário, suas 
formas tradicionais de reciprocidade para enfrentar os requisitos variáveis e temporários da força de trabalho, tecnologias, meios de produção e financiamento, são indubitavelmente constituintes da economia solidária.

É uma estrutura organizativa que constrói relações em rede a partir de realidades e potencialidades dos territórios. Estes espaços são denominados Espaços Territoriais de Capacitação e Reincorporação Social (ETCRS), atualmente são 24 distribuídos em todas as regiões do país (ver tabela 1).

Tabela 1 - Espaços Territoriais de Capacitação e Reincorporação (ETCR)

\begin{tabular}{|c|c|c|}
\hline Departamento & Município & ETCRs \\
\hline Antioquia & $\begin{array}{l}\text { Dabelba } \\
\text { Remédios } \\
\text { Ituango } \\
\text { Anorí }\end{array}$ & $\begin{array}{l}\text { ETCR Llanogrande } \\
\text { ETCR Carrizal } \\
\text { ETCR Santa lucia } \\
\text { ETCR La plancha }\end{array}$ \\
\hline Arauca & Arauquita & ETCR Filipinas \\
\hline Caquetá & $\begin{array}{l}\text { Motañita } \\
\text { San Vicente de Caguán }\end{array}$ & $\begin{array}{l}\text { ETCR Água Bonita } \\
\text { ETCR Miravalle }\end{array}$ \\
\hline Cauca & $\begin{array}{l}\text { Buenos Aires } \\
\text { Caldono } \\
\text { Miranda } \\
\text { Patía }\end{array}$ & $\begin{array}{l}\text { ETCR El Ceral } \\
\text { ETCR Los Monos } \\
\text { ETCR Monterredondo } \\
\text { ETCR El Estrecho }\end{array}$ \\
\hline Cesar & La paz & ETCR San José del Oriente \\
\hline Chocó & Carmen del Darién y Rio Sucio & ETCR Caracolí \\
\hline Guaviare & $\begin{array}{l}\text { San José del Guaviare } \\
\text { San José del Guaviare }\end{array}$ & $\begin{array}{l}\text { ETCR Las Colinas } \\
\text { ETCR Charras }\end{array}$ \\
\hline La Guajira & Fonseca & ETCR Pondores \\
\hline Meta & $\begin{array}{l}\text { La Macarena } \\
\text { Mesetas } \\
\text { Vista Hermosa }\end{array}$ & $\begin{array}{l}\text { ETCR Yarí } \\
\text { ETCR La Guajira } \\
\text { ERCR La Reforma }\end{array}$ \\
\hline Nariño & Tumaco & ETCR La Variante \\
\hline N.de Santander & Tibú & ETCR Caño Indio \\
\hline Putumayo & Puerto Asis & ETCR La pradera \\
\hline Tolima & $\begin{array}{l}\text { Planadas } \\
\text { Icononzo }\end{array}$ & $\begin{array}{l}\text { ETCR El Oso } \\
\text { ETCR La fila }\end{array}$ \\
\hline
\end{tabular}

Fonte: Agencia para la Reincorporación y Normalización (2020). 
O acesso e a titulação de terras pela cooperativa foram o primeiro ponto da agenda temática a ser abordado no marco da mesa de conversação entre o governo nacional e as FARC-EP em 2016. O objetivo da Reforma Rural Integral sugerida pelo grupo seria "contribuir com a transformação estrutural do campo, fechando as lacunas entre o campo e a cidade, criando condições para o bem viver para a população rural" (ACORDO DE PAZ FINAL, 2016, p. 5).

A ausência de políticas de distribuição de terras entre os projetos limita e muitas vezes impossibilita o desenvolvimento de projetos em Economia Solidária no espaço agrário, pois dificultam o acesso a créditos, a empréstimos que poderiam fomentar e potencializar estas experiências. Conforme Rodríguez (2015, p. 26):

O acesso à terra é determinado pelo poder político e pelo poder econômico, de modo que, se a terra também não é distribuída, é por isso que é importante ter um entendimento abrangente da terra, como uma categoria política e econômica ligada ao poder, mas também como o substrato onde as plantas são cultivadas, isto é, a terra como um espaço vital, onde a vida cresce e se desenvolve.

Por não terem o acesso à terra assegurado pelo governo, o coletivo arrenda terras a campesinos que possuem lotes próximos aos ETCRS possibilitando que estes também possam associar-se às cooperativas vinculadas a Ecomum. É importante salientar que este impasse provoca vulnerabilidade dos projetos produtivos, pois a ocorrência de alguma intempérie na produção comprometerá o pagamento do arrendo e assim homens e mulheres correm o risco de serem expulsos de seus territórios.

Citamos a questão da terra por ser tema central, mas é importante salientar que este não foi o único descumprimento do acordo assinado em 2016. A precária infraestrutura dos territórios (energia, água, gás), a falta de assistência técnica, jurídica, de inserção de homens e mulheres ao sistema de saúde, a segurança, são algumas das questões que os ex-combatentes precisam enfrentar em seus territórios e continuar exigindo politicamente ações do Estado. 
Em meio a tantos desafios, a cooperativa busca impulsionar, através de redes, a comercialização do que é produzido no campo e na cidade. De acordo com Bartra (2014) a realização progressiva e complexa de inumeráveis redes solidárias, sinergicamente integradas, não é nem uma ruptura imediata do sistema capitalista em uma determinada sociedade, nem tampouco uma reforma a tal sistema, mas a expansão efetiva de um novo sistema econômico, político e cultural anticapitalista que cresce negando-lhe as estruturas. Além das redes, também são realizadas, a nível nacional e até internacional, a participação em feiras, que buscam visibilizar e fortalecer o trabalho dos reincorporados.

Importante destacar, o interesse da Ecomum através de suas atividades é buscar a reincorporação coletiva, primando pelo trabalho em comunidade. Comunidade entendida como a expressão e o espaço de luta de interesses, articuladas as ações coletivas de reciprocidade e de reconhecimento (MEDINA, 2008).

Concordo que o acordo de paz foi um avanço e trouxe a oportunidade de a sociedade colombiana vislumbrar, depois de várias décadas, a ausência do cenário de confronto no espaço agrário (VILLAMIZAR, 2020). No entanto, é preciso ir além. O Estado necessita estar mais próximo aos territórios a partir das suas instituições e políticas públicas. Ouvindo o que homens e mulheres necessitam para impulsionar e garantir o desenvolvimento dos seus projetos produtivos. Acreditamos que esta ação consequentemente possibilitaria o aumento da produção e abastecimento agroalimentário interno.

A primazia de terras para o agronegócio exportador vem comprometendo o abastecimento de produtos agrícolas para o mercado interno e fazendo com que o país importe produtos até então produzidos historicamente em suas regiões como o café. De acordo com Villamizar (2010) as importações agrícolas e agroindustriais passaram de US \$ 637 milhões em 1992 para US $\$ 5.786$ milhões em 2015, ou seja, aumentaram 9,1 vezes. Este panorama representa o aumento da insegurança alimentar do país, principalmente nos grupos mais pobres localizadas nas zonas rurais. 
Entendemos que há um horizonte a ser construído junto a Ecomum, pelo governo, movimentos sociais, universidades, que enxerguem as potencialidades estratégica que esses projetos têm. E que, para além da produção e acesso aos mercados, isso possibilitaria a reincorporação efetiva de homens e mulheres que almejam viver de maneira digna em seus territórios.

\section{Considerações Finais}

A alta concentração de terras na Colômbia e a primazia do Estado em apoiar projetos de agropecuária extensiva causam impactos socioambientais de várias magnitudes, como a expulsão de camponeses, permanência de guerrilhas, violência paramilitar, destruição da natureza e o número elevadíssimo de assassinato de líderes sociais, outros. Consequências que expressam o conflito e a tensão permanente no espaço agrário e a centralidade histórica da questão agrária colombiana.

Em meio a essa tensão, vislumbramos experiências e resistências que estão sendo construídas desde abaixo, em territórios camponeses, afro-colombianos e indígenas com princípios de solidariedade, respeito à natureza e autonomia territorial que se contrapõem ao paradigma desenvolvimentista do capitalismo agrário.

Destacamos a importância da Economia Social e Solidária como base para as atividades produtivas que emergem no espaço agrário colombiano e como este paradigma coaduna com os princípios da Economia Camponesa. Trazemos para análise a cooperativa Ecomum. Resultante do acordo de paz de 2016, esta foi o meio escolhido pelos ex-combatentes para reincorporação coletiva. Espacializa-se em todo território nacional, conta com mais de 3.000 associados e explicita uma gama de lutas, dentre elas, o acesso a terras para desenvolvimento dos projetos produtivos.

Há três anos, homens e mulheres diante de muitas dificuldades mostram suas potencialidades através da produção prioritariamente agrícola que poderia, estrategicamente, ser aproveitada pelo governo em suas várias dimensões para produção de alimentos e abastecimento interno, diminuindo as importações e garantindo a segurança alimentar do país. 
Acreditamos que os projetos produtivos devem ser apoiados para ir além dos seus territórios, tanto no campo como na cidade, visibilizando assim as colheitas até então invisíveis (BARTRA, 2011) pela sociedade colombiana, amenizando o estigma que estes homens e mulheres carregam e possibilitando a inserção social e econômica destes de maneira efetiva.

Presente na sigla da cooperativa, o princípio e a prática social do comum devem estar presentes no cotidiano dos Espaços Territoriais de Capacitação e Reincorporação (ETCR), onde a associação política e econômica fortalecerá e viabilizará conquista de direitos comuns e sua autonomia. 


\section{REFERÊNCIAS}

BARBIERI, F. Globalización, libre comercio y desarrollo rural. [S.l.s.s.n.], 2011. Conferencia dictada em el marco de la cátedra Manuel Ancízar "Tierras y issealda" de la Universidad Nacional de Colombia. 12 de mayo de 2011.

BARTRA, A. Os Novos camponeses: leituras a partir do México profundo. São Paulo: Cultura Acadêmica; Cátedra Unesco de Educação do Campo e Desenvolvimento Rural, 2011.

BARTRA, A. Resistir em los pies sobre la tierra: experiencia mexicana. In: RODRÍGUEZ M; CAMACHO; MORALES (Ed.). Concentración, acaparamiento de tierras, desarrollo rural y derecho a la alimentación. Bogotá: FIAN-Colômbia; ICANH-Universidad Externado de Colombia. 2017.

CNMH. Em nación desplazada: informe del desplazamiento forzado em Colombia. Bogotá, D.C: CNMH-UARIV, 2015. Disponible em: https://bit.ly/29uyNzv. Acceso en: 25 fev. 2020. COLOMBIA. Presidencia de la República. Oficina del Alto Comisionado para la Paz. Acuerdo Final para la Terminación del Conflicto y la Construcción de una Paz Estable y Duradera. [S.l.s.n.]. 2016. DANE-DEPARTAMENTO ADMINISTRATIVO NACIONAL DE ESTADÍSTICA. Tercer Censo Nacional Agropecuario: hay campo para todos. Bogotá: DANE, 2016. 
FAJARDO, M. D. Territorios de la agricultura colombiana. Bogotá: Universidad Externado de Colombia, 2009.

FERNANDES, B. M. Cuando la agricultura familiar es campesina. In: HIDALFO, F. Agriculturas campesinas em Latinoamérica: propuestas y isseal. Quito: Editorial IAEN, 2014.

MEDINA, P. (Coord.). Educación intercultural em América Latina: memorias, horizontes históricos y disyuntivas políticas, UPN/PLAZA y VALDÉS/CONACYT, México. [S.l.:s.n.], 2008.

OXFAM. Radiografía de la issealdade: lo que nos isse el último censo agropecuário sobre la distribución de la tierra en Colombia. [S.l.:s.n.], 2017. Disponible en: https://goo.gl/Tb7BKz. Acceso en: 18 fev. 2020. RAZETO, L. En el factor " $C$ " “Charla de Luis Razeto", Escuela de Cooperativa "Luis Arrona". S.l.s.n.], 1997.

PORTO-GONÇALVES, C. W. A Reinvenção dos Territórios na América Latina/Abya Yala. [S.l.]: Universidad Nacional Autónoma de México; Instituto de Investigações Sociais, 2012.

RODRÍGUEZ M; CAMACHO; MORALES (Ed.). Concentración, acaparamiento de tierras, desarrollo rural y derecho a la alimentación. Bogotá: FIAN-Colômbia; ICANH: Universidad Externado de Colombia, 2017.

RODRÍGUEZ, F. B. Economías para la paz enmedio de la guerra: el reto de la economía social. In: EL TEMA de tierras y desarrollo rural en el acuerdo preliminar para la terminación del conflicto y la construcción de una paz estable y duradera: reflexiones preliminares. Bogotá:

Corporación Grupo Semillas, 2015.

VILLAMIZAR, J. C. La reforma agraria: la paz con las farc, un compromiso aplazado de nuevo. Anuário Colombiano de Historia Social y de la Cultura, v. 47, n. 1, p. 231-263, 2020. 